\title{
Social Accountability and community participation in Village Health Nutrition and Sanitation committees in Uttar Pradesh
} Amith Nagaraj Bathula ${ }^{1}$, Lakshmi Sripada ${ }^{2}$, Lincoln P. Choudhury ${ }^{3}$

${ }^{1}$ Master's in Social Work, Roda Mistry College of Social Work, Hyderabad; ${ }^{2}$ Master's in Social Work, Tata Institute of Social Sciences, Mumbai; ${ }^{3}$ Master's in Public Health, Sree Chitra Tirunal Institute for Medical Sciences \& Technology, Trivandrum, Kerala

\begin{tabular}{|c|c|c|c|c|c|c|c|}
\hline Abstract & Introduction & Methodology & $\underline{\text { Results }}$ & $\underline{\text { Conclusion }}$ & $\underline{\text { References }}$ & $\underline{\text { Citation }}$ & Tables / Figures \\
\hline \multicolumn{8}{|c|}{ Corresponding Author } \\
\hline \multicolumn{7}{|c|}{$\begin{array}{l}\text { Mr. Amith Nagaraj Bathula, } 70 \text { Lodi Estate, New Delhi - } 110003 \\
\text { E Mail ID: bnagraj@worldbank.org }\end{array}$} & \\
\hline
\end{tabular}

\section{Citation}

Bathula AN, Sripada L, Choudhury LP. Social Accountability and community participation in Village Health Nutrition and Sanitation committees in Uttar Pradesh. Indian J Comm Health. 2020;32(1):108-113.

Source of Funding: Nil Conflict of Interest: None declared

Article Cycle

Received: 10/02/2020; Revision: 20/02/2020; Accepted: 10/03/2020; Published: 31/03/2020

This work is licensed under a Creative Commons Attribution 4.0 International License.

\section{Abstract}

Background: A First step towards community involvement is Participation. The government of India under its flagship program, the National Health Mission, advocates and actively encourages community participation and has setup Village Health Nutrition and Sanitation Committees (VHNSCs) at village level. Aim \& Objective: The objective of this paper is to examine "The Level of Community Participation in the Village Health Sanitation committees" in the state of Uttar Pradesh. Methods and Material: A cross-sectional mix method study was undertaken in 3 districts, covering 15 villages, in Uttar Pradesh between August to October 2019. The quantitative component included a pre-tested semi structured questionnaire. Further, Focused group discussion (FGDs) and key informant in-depth interview were undertaken for more information. Informed consent was collected from all the participants. The quantitative data was analyzed using SPSS 21.0 while the qualitative data was analyzed manually, based on themes. Results: The average size of the household was 5, 65\% respondents were educated, $88 \%$ were Hindus, $47 \%$ were from other backward class and $50 \%$ had below poverty line cards. In the year $2019,7 \%$ of the respondents participated in the Gram Sabha and 5\% in village health nutrition and sanitation committee meetings. Statistically significant variations were noticed where less than $20 \%$ of the schedule castes and schedule tribes had lower participation than other castes in any of the village level committees. Lack of time was one the key reasons cited for non-participation. Conclusions: To ensure adequate participation from all castes it is important to schedule meetings at times convenient may encourage more community participation.

\section{Keywords}

Village Health Nutrition and Sanitation Committee; Social Accountability; Community Involvement; Community Participation

\section{Introduction}

In line with the global call for achievement of the Sustainable Development Goals by 2030, improving access to primary care in countries like India is considered a public health priority. (1) Community engagement in the planning, delivery and monitoring of health services is essential component, as outlined in the national health policy 2017. (2) Synthesis of global knowledge and experience from India advocates for community engagement not only as a tool for improvement of health sector but also for enhancement of local governance, which can benefit the health indicators directly and indirectly. $(3,4)$

There is a growing research and evidence in the area of community participation. However, there is no conclusive evidence to refute or accept community participation. A recently concluded review, though could not determine the effect, did provide guidance on moving from individual tokenism to meaningful engagement with the community to ensure better outcomes.(5) The findings of the review is echoed in a study on four communities elsewhere, where with structured approach most of the community 

groups were able to develop locality specific approaches.

(6)

The national policy realized in the form of Village Health Nutrition and Sanitation Committees hereby referred to as VHNSCs at the Village level, is designed to ensure community participation and play leadership role in governance of health services. $(7,8)$

\section{Aims \& Objectives}

To examine the level of Community Participation in the Village Health Nutrition and Sanitation committees in Uttar Pradesh.

\section{Material \& Methods}

\section{Study design and study population:}

The study was a cross sectional, mix method study conducted in three districts of Uttar Pradesh. Five villages from each district were selected for detail data collection. The study participants for quantitative study were household members from the age group of 19 to 45 . For qualitative study, all the participants were above 18 years. The VHNSC members participated in the Focused group discussions while key informants like Auxiliary Nurse Midwives (ANMs), Anganwadi workers and Panchayati Raj members participated in the key informant interviews.

\section{Sampling and sample size determination}

Based on fixed criteria and using standard tools, annual performance analysis was undertaken by the state health department for all the districts which were graded as poor, medium or high performing category. Three districts (one each from poor, medium and high performance) were selected as per district rank by department of health for the year of 2015-2016. Within each district 5 villages were selected for detail data collection. The total population of these 15 villages was 26883. As per National Family health Survey-4, for institutional deliveries, $67 \%$ of rural population goes to private sector and, $44.5 \%$ happen in public sector. (9) For sample size calculations, 33\% accessing the public sector were considered with $95 \%$ confidence level, $5 \%$ confidence interval the sample size was 336 , Assuming $15 \%$ non-response rate the sample size was 386 , rounding off to the nearest number it is 400 . As the interviews were to be conducted in the household level among adults between 18-45 years, 25\% more sampling was done with final sample size of 500 .

\section{Study tool}

A total of five domains namely: (i) Access and availability of health and nutrition services. (ii) Level of satisfaction with health and nutrition services, (iii) Knowledge and awareness about the health care and nutrition services, (iv) Community involvement and participation in planning and implementation of health and nutrition services and (v) Transparency and accountability in health and nutrition services were identified to address the research question. These domains were captured in a pre-tested semi structured questionnaire for households, guides for conducting qualitative interviews through Focused group discussions and Key Informant interviews. Each tool captures a different domain, varied levels of indicators and information that contributes to the study. The household schedule had 51 questions covering all the five domains, whereas the FGDs with VHSNCs have 17 points in the checklist that cover only three domains. The guide for KII had 50 points of enquiry. The tools had comprehensively covered the perception of all key players that were important for addressing the study objectives. This paper mainly focuses on 2 domains: Community Involvement and Community Participation. The detailed results of other domains are being shared elsewhere.

\section{Ethical consideration}

The Institutional review board of the Tata Institute of Social Sciences provided the clearance for the study on 11th July 2018. Individual consent form was administered to the participants of FGDs, key informant and household interviews. The informed consent was later translated into the local language for reference of the respondents. The data entry was done in the computer of the Principal investigator after removal of individual identifier. The soft copy of the data is stored with the principal investigator to avoid any misuse of data. The hard copy of data is kept in safe place as per the administrative process of Tata Institute of Social Sciences.

\section{Data collection}

Quantitative data: The Anganwadi Centres of each village had a detailed household list. The information on households was collected from Anganwadi workers with family members in the age group of 18-45 years or households with children less than 5 years to finalize exhaustive list of participants. In-order to capture the community perception, data was collected from 10 households, randomly selected from the Anganwadi list of household numbers, using rand function of spread sheet on the first day of data collection. Factoring in nonavailability of respondents or their refusal to participate, additional $50 \%$ of households were sampled making the initial list as 15 households per village. Overall, a total of 500 households provided their responses.

Qualitative data: The data on functioning of VHNSCS was collected from following members-Chairman of the committee, Women representative and any other member using the FGD. One FGD with VHNSC members was conducted in each village leading to an overall 15 FGDs. The key informant's interview was undertaken with Anganwadi workers, Auxiliary nurse-wife (ANMs), and head of Gram Panchayat. A total of 30 structured interviews were conducted with key informants. The data collection was conducted from August to October 2018.

\section{Data analysis}

The data was analyzed using Statistical Package for Social Sciences (SPSS-IBM version 21.0). Proportions and mean values were calculated. After applying the tests of normality, Chi square test was applied, and odds ratios were calculated. $P$ value of $<0.05$ was significant. The 
qualitative data was translated from Hindi to English. The content analysis of qualitative data was done manually as per the themes.

\section{Results}

The average size of the household is 5.10 [range 1-14] members in the family which is consistent across districts, class and religious groups. The majority (47\%) belonged to Other Backward Castes (OBCs) category and almost 88 $\%$ are Hindus. More than $50 \%$ had BPL cards at the time of data collection. (Table 1) The average household income is Rs. 70,600 per annum (Rs 0-1,50,000). About 65 $\%$ of head of the households were educated ( $11 \%$ primary and $54 \%$ secondary and above) and the remaining $35 \%$ were illiterate. Similarly, mother's education - a key factor for child health outcomes - had a wide distribution, with almost a $49 \%$ of the sample having no formal education (illiterate), $13 \%$ had attended up to primary education and remaining $38 \%$ that had above secondary education.

Six percent of the respondents were either part of any village level group or committees (Figure 1) and (Figure 2) with district wise variations i.e. Chandoli-2.78\%, Hapur$3.5 \%$ and Kushinagar-12\%. Participation was highest from Muslim community which reported $11 \%$ participation in village level groups followed by Hindus at $6 \%$. Only $8 \%$ of the households have reported to be contacted by VHSNCs to understand health related problems, little less than $5 \%$ who have attended VHSNC meetings in last one year and $7 \%$ who have attended Gram Sabha meeting to discuss about health issues in the village.

Statistically significant variation (with $p$ value $<0.05$ ) was found (Table 2) with the variables such as district and caste of the households in their participation in VHNSCS and Village committees with significantly more people from Kushinagar where other backward caste or upper caste participated in the Gram Sabha, or decisions at Gram Sabha on health or Village health committee. About $69 \%$ of the households were willing to contribute for the development of programmes even if they don't get any direct benefit, and $78 \%$ households have reported to come together to resolve the water issues in the village, while less than one-fourth were willing to give their time for such activities. (Figure 2)

About $45 \%$ of the households have participated to rate their health programs in the village, $22 \%$ have physically participated in the development activities in the village in some or the other form. The FGD with VHSNC members has put more light on the representation of the committee members, it was found that more than $40 \%$ of the key positions such as president and vice-president are filled with members from the upper caste, who did not necessarily represent the larger community. When explored further, it was told that the selection of the key positions was done on the bases of literacy levels, on better understanding about the village and liaise with higher officials. On the contrary, some Village Pradhans were unable to even comprehend the proper way to utilize the Untied Fund of Rs. 10,000 that was disbursed to them for carrying out functions and activities of VHSNCs. The FGD findings also informed that VHSNCs had been set up in almost all villages. However, the awareness levels of their existence were very poor indicating their poor visibility. Also, in many cases committee meetings were not being conducted regularly.

"Hum tho bahut bullate hai, lekin logon ke pass time he nahin hai... jab jarurat padti hai tho veh Pradhan ya local political leader se kam karvate hai.." VHSNC member.

Most of the Gram Pradhans did mention about the public announcement on health programs and introduced the VHSNC members during the Gram Sabha. However, issues pertaining to health were associated with a certain taboo like sickness etc.

"Gaon ke log tho bahut kutch karna chahte hai Goan ke udhar ke leye, parantu health service tho government dete hai, tho kutch jyada interest nahi hai..." Village Pradhan

\section{Discussion}

The community in the study villages have high motivation levels for Community involvement and participation in planning and implementation of developmental activities. However, there has been very low level of participation for health and nutrition services. The community is ready to contribute in monetary terms but not willing to give their time to participate in the development activities or discussions especially on health-related issues.

Improving better participation: One of the key requirements for social accountability mechanisms to work is the social integration among villagers. The higher the extent of integration, the greater is the possibility that people would be willing to come together for exacting accountability from various service providers. The VHNSCS have made marginal efforts towards community mobilisation that could have translated into increased involvement and participation of community members for improving health service uptake. Tools like invited spaces for initiating better dialogue and the accommodating perspectives is as important as the frequency and the modalities of the discussion on overall village microcosm in which health issues can be imbedded. (10) Other methods like inducing participation or bringing a third party to play the role of facilitator may result in better participation. These third parties can be NGOs or external stakeholders. $(4,11)$

Implementation of community mobilization: No targeted interventions were planned to ensure community participation in any of the health programs for improving their participation in the VHNSC meetings. Only select members were informed through messages making it unclear on how this can be considered as an effort 
towards ensuring larger participation. As the rules of community engagement are improving constantly it was not clear how far the community is understanding the newer provisions under the government efforts. Also, the limitation of funds for local level activities is a constraint. Studies from India have found out that with continuous financial support and appropriate technical support it is possible to improve the community participation. (12)

Why representation? The caste differences in community participation are very significant. One can argue that better representation may influence better outcomes. However, a study from Odisha found out that the same may not be linearly related, and is dependent on what is expected role of the community members (13) in VHNSCs. However, the encouraging eagerness to contribute to the community development both by the households and key stakeholders have confirmed their sense of belongingness. However, they do come together swiftly for the issues which are relevant to their day to day needs. Health is perceived as an occasional need, and they consider the government health services as free goods which is part of their entitlement and they don't have to make additional efforts to get it at desired quality. Representation and participation go hand in hand.

No spare time: Contrary to the popular belief of availability of disposable spare time in rural areas, fewer people were willing to contribute their time for the functioning of VHNSCs. From the point of view of requirements for social accountability mechanisms contribution of time to these causes is far more important than financial contribution. This may be due to less participation of people in the committee meetings which leads to their lack of knowledge on the workings of committee and in return makes them less interested for future participation. (15) This vicious cycle is hampering the participation of members in VHNSCs.

\section{Conclusion}

The participation of people, in general, is low in the village level meetings. The composition of committees is leaning more towards upper cast people, which is not a true representation of the larger/majority community at the village level. However, if motivated there is a willingness amongst the community members to contribute to the overall development of the villages and especially for the health initiatives.

\section{Recommendation}

Equal representation of members from different castes in the VHNSCs can be the game changer and enhance the community participation. Better communication with the beneficiaries on a regular basis can build the trust and encourage people to provide their inputs and actively participate in the government programs and in turn will help in a systematic diagnosis to assess the demand for services. Given the interest levels of the community members are high, they must be channelized in the right direction for development activities.

\section{Limitation of the study}

The study design was limited to three districts in Uttar Pradesh. However, it was well distributed to capture many regional differences existing in the state. Thus, the findings of the study must be inferred with the perspective of understanding patterns of VHNSCs participation in the whole state.

\section{Relevance of the study}

Community participation is considered as an integral part of the National Rural Health Mission in the early 2000. Participation is an important first step towards the role's community was expected to play like planning, implementation and monitoring of the nation-wide program and voice to people. The study findings presented here provide a basic insight of community participation in this crucial structure for health delivery at the village level and thus how far it can carry forward the spirit of National Health Mission (which subsumed NRHM) at the village level.

\section{Authors Contribution}

All Author have contributed equally.

\section{References}

1. Gera R, Narwal R, Jain M, Taneja G, Gupta S. Sustainable development goals: Leveraging the global agenda for driving health policy reforms and achieving universal health coverage in India. Vol. 43, Indian Journal of Community Medicine. Wolters Kluwer Medknow Publications; 2018. p. 255-9.

2. Ministry of Health and Family Welfare. Government of India. National Health Policy 2017. 2017.

3. The World Bank. Localizing Development Does Participation Work? 2013.

4. Menon S, Hartz-Karp J. Institutional innovations in public participation for improved local governance and urban sustainability in India. Sustain Earth [Internet]. 2019 Dec 16 [cited 2020 Jan 8];2(1):6. Available from: https://sustainableearth.biomedcentral.com/articles/10.1186/s42 055-019-0013-x

5. Kenny A, Farmer J, Dickson-Swift Phd V, Hyett Mhsc N, Student L, Rural LT, et al. Community participation for rural health: a review of challenges.

6. Farmer J, Nimegeer A. Community participation to design rural primary healthcare services [Internet]. 2014 [cited 2020 Jan 8]. Available from: http://www.biomedcentral.com/14726963/14/130

7. Village Health Sanitation \& Nutrition Committee :: National Health Mission [Internet]. [cited 2020 Jan 8]. Available from: https://nhm.gov.in/index1.php?lang=1\&level=1\&sublinkid=149\&li $\mathrm{d}=225$

8. National Health Mission. Government of India. Handbook for members of village health sanitation and nutrition committee.

9. International Institute for Population Sciences (IIPS) and ICF. National Family Health Survey(NFHS-4) 2015-16: Uttar Pradesh [Internet]. 2017 [cited 2020 Jan 10]. Available from: http://www.rchiips.org/nfhs

10. Madon S, Krishna S. Challenges of accountability in resource-poor contexts: lessons about invited spaces from Karnataka's village health committees. Oxford Dev Stud. 45:522-41. 
INDIAN JOURNAL OF COMMUNITY HEALTH / VOL 32 / ISSUE NO 01 / JAN - MAR 2020

11. Patel G, Garimella S, Scott K. Doing implementation research on health governance: a frontline researcher's reflexive account of field-level challenges and their management. Int J Equity Heal. 16:1-10.

12. Ved R, Sheikh K, George AS, Raman VR. Village Health Sanitation and Nutrition Committees: Reflections on strengthening community health governance at scale in India. BMJ Glob Heal. 2018 Jan 1;3.

13. Srivastava A, Gope R, Nair N, Rath S, Rath S, Sinha R, et al. Are village health sanitation and nutrition committees fulfilling their roles for decentralised health planning and action? A mixed
[Social Accountability] | Bathula AN et al methods study from rural eastern India. BMC Public Health. 2016 Jan 22;16(1).

14. Behera B, Mishra P. Democratic Local Institutions for Sustainable Management and Use of Minor Irrigation Systems: Experience of Pani Panchayats in Odisha, India. Water Econ Policy. 2018 Jul $1 ; 4(3)$.

15. Dierickx S, O’Neill S, Gryseels C, Immaculate Anyango E, BannisterTyrrell $\mathrm{M}$, Okebe J, et al. Community sensitization and decisionmaking for trial participation: A mixed-methods study from The Gambia. Dev World Bioeth [Internet]. 2018 Dec 16 [cited 2020 Jan 11];18(4):406-19.

\section{Tables}

\section{TABLE 1 HOUSEHOLD SOCIO ECONOMIC PROFILE OF RESPONDENTS}

\begin{tabular}{|l|c|}
\hline District & $\%$ age \\
\hline Chandoli & $144(29 \%)$ \\
\hline Hapur & $200(40 \%)$ \\
\hline Kushinagar & $156(31 \%)$ \\
\hline Caste Category & $134(27 \%)$ \\
\hline SC & $23(5 \%)$ \\
\hline ST & $234(47 \%)$ \\
\hline OBC & $12(2 \%)$ \\
\hline General & $97(19 \%)$ \\
\hline Others & \\
\hline Religion & $439(88 \%)$ \\
\hline Hindu & $38(8 \%)$ \\
\hline Muslim & $23(5 \%)$ \\
\hline Other & $217(43 \%)$ \\
\hline BPL Card Status & $251(50 \%)$ \\
\hline APL & $32(7 \%)$ \\
\hline BPL
\end{tabular}

\section{TABLE 2 CROSS TABULATION}

\begin{tabular}{|c|c|c|c|c|c|c|c|c|c|}
\hline \multirow[b]{2}{*}{ Variables } & \multicolumn{3}{|c|}{$\begin{array}{l}\text { Participated in any community } \\
\text { activities in last } 12 \text { months }\end{array}$} & \multicolumn{3}{|c|}{$\begin{array}{c}\text { Ever participated in the Gram Sabha } \\
\text { for decision related to any health plan } \\
\text { or program }\end{array}$} & \multicolumn{3}{|c|}{$\begin{array}{l}\text { Attended any Village Health, } \\
\text { Sanitation Nutrition Committee } \\
\text { meeting in the past year }\end{array}$} \\
\hline & No & Yes & p-Value & No & Yes & P-Value & No & Yes & p-Value \\
\hline \multicolumn{10}{|l|}{ Districts } \\
\hline Chandoli & 135(93.8\%) & $9(6.3 \%)$ & $<.001$ & $139(96.5 \%)$ & $5(3.5 \%)$ & 0.009 & $144(100 \%)$ & $0(0 \%)$ & 0.001 \\
\hline Hapur & 167 (83.5\%) & $33(16.5 \%)$ & & 178 (89\%) & $22(11.0 \%)$ & & $183(91.5 \%)$ & $17(8.5 \%)$ & \\
\hline Kushinagar & 88 (56.4\%) & $68(43.6 \%)$ & & 149 (95.5\%) & $7(4.5 \%)$ & & $150(95.4 \%)$ & $6(4.6 \%$ & \\
\hline \multicolumn{10}{|l|}{ Economic category } \\
\hline APL & 177(81.6\%) & $40(18.4 \%)$ & 0.002 & 202(93.1\%) & 15 (6.9\%) & 0.069 & $208(95.9 \%)$ & $9(4.1 \%)$ & 0.334 \\
\hline $\mathrm{BPL}$ & $182(72.5 \%)$ & $69(27.5 \%)$ & & $233(92.8 \%)$ & $18(7.2 \%)$ & & 237 (94.4\%) & $14(5.6 \%)$ & \\
\hline Others & $31(96.9 \%)$ & $1(3.1 \%)$ & & $31(96.9 \%)$ & $1(3.1 \%)$ & & $32(100 \%)$ & $0(0 \%)$ & \\
\hline \multicolumn{10}{|l|}{ Religion } \\
\hline Christian & $20(87 \%)$ & $3(13.0 \%)$ & 0.208 & $22(95.7 \%)$ & $1(4.3 \%)$ & 0.584 & $23(100 \%)$ & $0(0 \%)$ & 0.121 \\
\hline Hindu & $344(78.4 \%)$ & $95(21.6 \%)$ & & $410(93.4 \%)$ & $29(6.6 \%)$ & & $420(95.7 \%)$ & $19(4.3 \%)$ & \\
\hline Muslim & $26(68.4 \%)$ & $12(36.1 \%)$ & & $34(89.5 \%)$ & $4(10.5 \%)$ & & $34(89 \%)$ & $4(10.5 \%)$ & \\
\hline \multicolumn{10}{|l|}{ Cast } \\
\hline General & $7(58.3 \%$ & $5(41.7 \%)$ & 0.009 & $11(97.1 \% 0$ & $1(8.3 \%)$ & 0.057 & $11(91.7 \%)$ & $1(8.3 \%$ & 0.027 \\
\hline Other Backward Class & $169(72.2 \%)$ & $65(27.5 \%)$ & & $217(92.7 \%)$ & $17(7.3 \%)$ & & $219(93.6 \%)$ & $15(6.4 \%)$ & \\
\hline Schedule Caste & $114(85.1 \%)$ & $20(14.9 \%)$ & & $127(94.8 \%)$ & $7(5.2 \%)$ & & $131(97.8 \%)$ & $3(2.2 \%)$ & \\
\hline Schedule Tribe & $20(87.0 \%)$ & $3(13.0 \%)$ & & $20(87 \%)$ & $3(13 \%)$ & & $19(82.6 \%)$ & $4(17.4 \%)$ & \\
\hline \multicolumn{10}{|l|}{ House Ownership } \\
\hline House Owned & $380(78 \%)$ & $107(22 \%)$ & 0.924 & $454(93.2 \%)$ & $33(6.8 \%)$ & 0.897 & $464(95.3 \%)$ & $23(4.7 \%)$ & 0.422 \\
\hline House not Owned & $10(76.9 \%)$ & $3(23.1 \%)$ & & $12(92.3 \%)$ & $1(7.7 \%)$ & & $13(100 \%)$ & $0(0 \%)$ & \\
\hline \multicolumn{10}{|l|}{ Electricity Connection } \\
\hline No & $115(81 \%)$ & $27(19 \%)$ & 0.31 & $139(97.3 \%)$ & $3(2.1 \%)$ & 0.009 & $140(98.6 \%)$ & $2(1.4 \%)$ & 0.032 \\
\hline Yes & $275(76.8 \%)$ & $83(23.2 \%)$ & & $327(91.3 \%)$ & $31(8.7 \%)$ & & $337(94.1 \%)$ & 21 (5.9\%) & \\
\hline \multicolumn{10}{|l|}{ Toilet in House } \\
\hline No & $93(76.9 \%)$ & $28(23.1 \%)$ & 0.728 & $112(92.6 \%)$ & $9(7.4 \%)$ & 0.749 & $120(99.2 \%)$ & $1(0.8 \%)$ & 0.023 \\
\hline Yes & $297(78.4 \%)$ & $82(21.6 \%)$ & & $354(93.4 \%)$ & $25(6.6 \%)$ & & $357(94.2 \%)$ & $22(5.8 \%)$ & \\
\hline
\end{tabular}




\section{Figures}

\section{FIGURE 1 COMMUNITY MOBILIZATION AND PARTICIPATION}

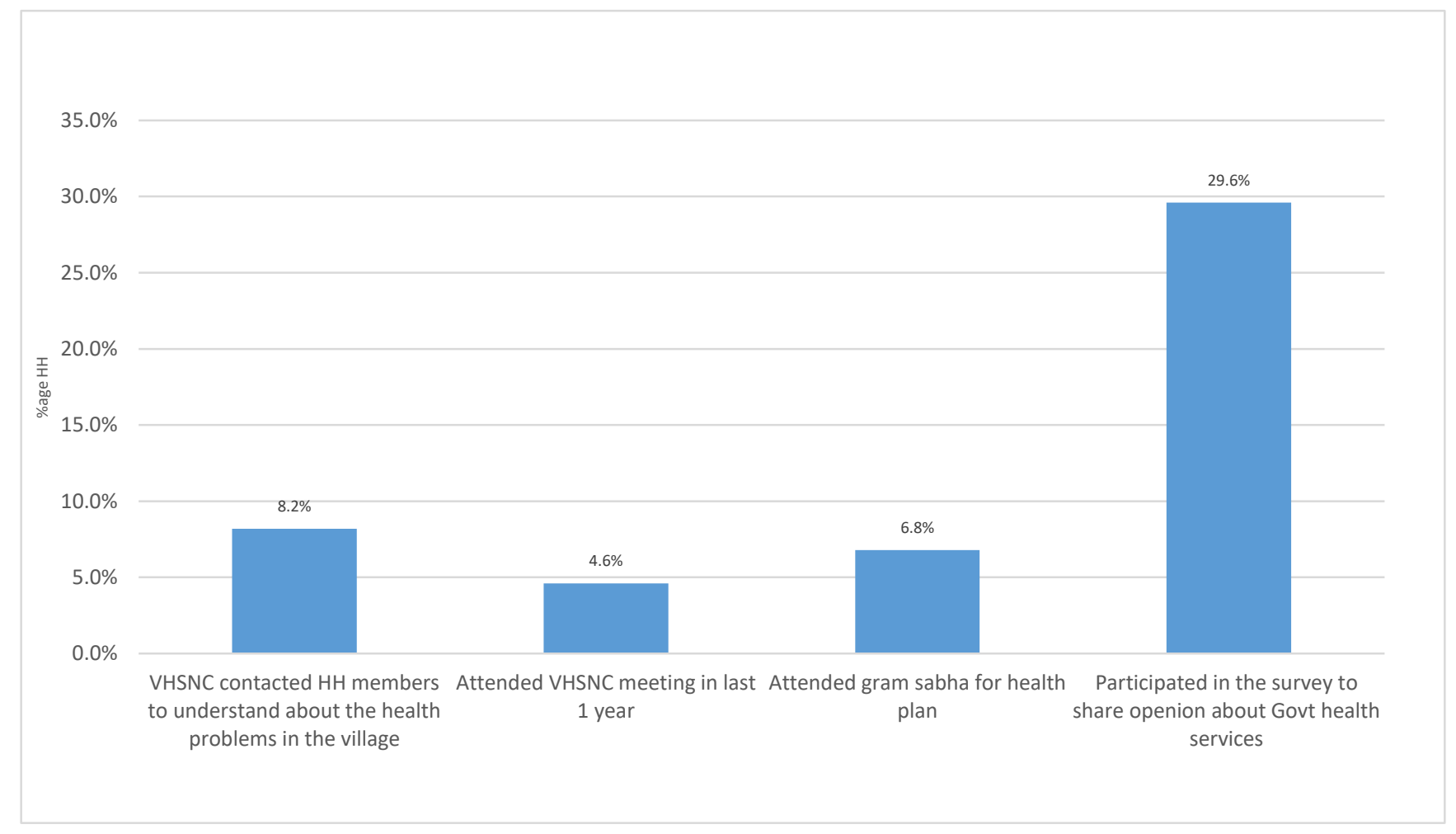

\section{FIGURE 2 COMMUNITY PARTICIPATION IN OTHER DEVELOPMENT ACTIVITIES}

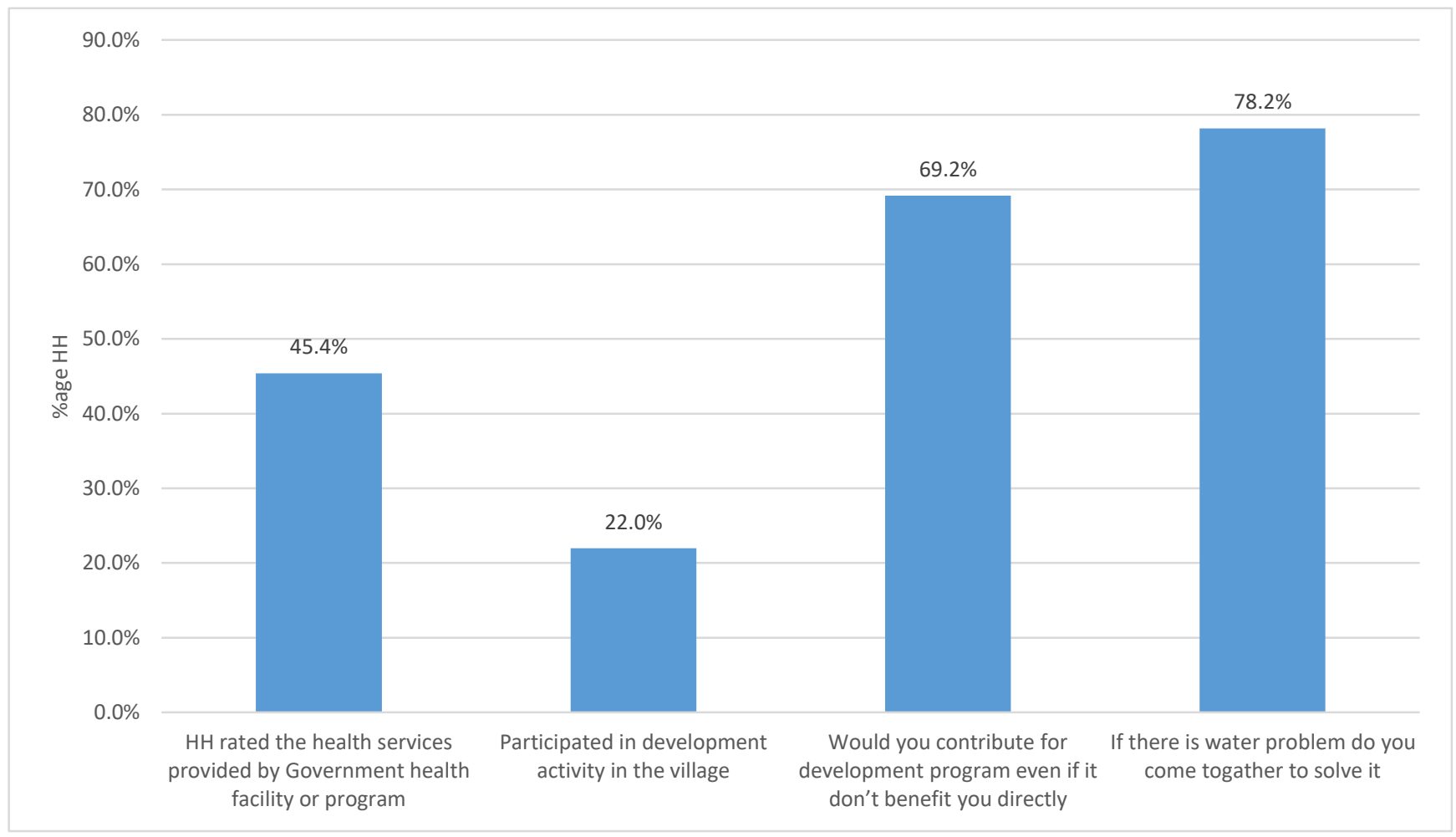

